\title{
High potassium concentration in a parenteral preparation of glyceryl trinitrate Need for caution if given by intracoronary injection
}

\author{
S C WEBB, R CANEPA-ANSON, A F RICKARDS, P A POOLE-WILSON
}

From the Cardiothoracic Institute and National Heart Hospital, London

SUMMARY Glyceryl trinitrate (Tridil) was given by intracoronary injection to a patient who developed coronary artery spasm during angioplasty. Transient exacerbation of chest pain and electrocardiographic changes occurred. This formulation of the drug contains a high concentration of potassium ions and should not be given by this route.

Intracoronary injection of glyceryl trinitrate has been recommended for controlling acute coronary artery spasm occurring during routine cardiac catheterisation or percutaneous transluminal angioplasty. $12 \mathrm{We}$ report a case where this form of treatment, given for spasm of the left anterior descending coronary artery after percutaneous transluminal angioplasty, caused transient exacerbation of angina and electrocardiographic changes. These events were associated with an increase in the coronary sinus potassium concentration resulting from potassium contained in the vehicle for the drug.

\section{Case report}

A 58 year old woman was investigated because of increasing angina resistant to conventional medical treatment. Treadmill exercise testing provoked typical chest pain without appreciable electrocardiographic changes, but Holter monitoring showed ST segment depression in lead CM5 during spontaneous pain and rapid atrial pacing. Coronary angiography showed a severe proximal stenosis of the left anterior descending coronary artery which was considered to be suitable for percutaneous transluminal angioplasty. At the start of the procedure a potassium sensitive electrode was positioned in the coronary sinus as part of a study on the effect of transient coronary artery occlusion. Angioplasty was performed using a Grüntzig balloon catheter (Schneider-Medintag GA-20-30) inflated to $5 \mathrm{bar}$ for $20 \mathrm{~s}$. The initial mean pressure gradient across the stenosis was $60 \mathrm{mmHg}$.

After the third dilatation the patient developed chest pain accompanied by ST segment depression in lead CM5. Angiography showed occlusion of the left anterior descending coronary artery with some extravasation of dye suggesting plaque rupture and arterial spasm. Intracoronary injections of glyceryl trinitrate (Tridil $250 \mu \mathrm{g} / \mathrm{ml}$ ) were given in boluses of $125 \mu \mathrm{g}$ on seven occasions and $250 \mu \mathrm{g}$ once. Each injection was followed by a transient exacerbation of the patient's chest pain with electrocardiographic changes. The smaller dose caused an increase in ST segment depression (Fig a), while injection of $250 \mu \mathrm{g}$ caused ST segment elevation and T wave peaking, which persisted for 2 minutes (Fig b). After each bolus of glyceryl trinitrate the coronary sinus potassium concentration rose transiently by between 0.9 and $2.6 \mathrm{mmol} / \mathrm{l}$ (mean $1.55 \mathrm{mmol} / \mathrm{l}, \mathrm{n}=8$ ). The increase in coronary sinus potassium concentration occurred about $4 \mathrm{~s}$ after each injection and persisted for between 12 and $30 \mathrm{~s}$.

Glyceryl trinitrate was then given intravenously by bolus injections ( $250 \mu \mathrm{g}$ twice) followed by an infusion $(40 \mu \mathrm{g} / \mathrm{min})$. The patient's chest pain subsided, and the electrocardiogram returned to normal. Angiography confirmed that the left anterior descending coronary artery was patent with reduction of the severity of the stenosis. Recovery was uneventful, and the patient has no further angina. Treadmill exercise testing was negative and did not provoke chest pain.

\section{Discussion}

The transient rise in coronary sinus potassium concentration after each intracoronary injection of glyceryl trinitrate suggested that a bolus of fluid rich in potassium had passed through the coronary circulation. Tridil is supplied in $10 \mathrm{ml}$ ampoules containing $5 \mathrm{mg}$ of glyceryl trinitrate stabilised by alcohol, lac- 


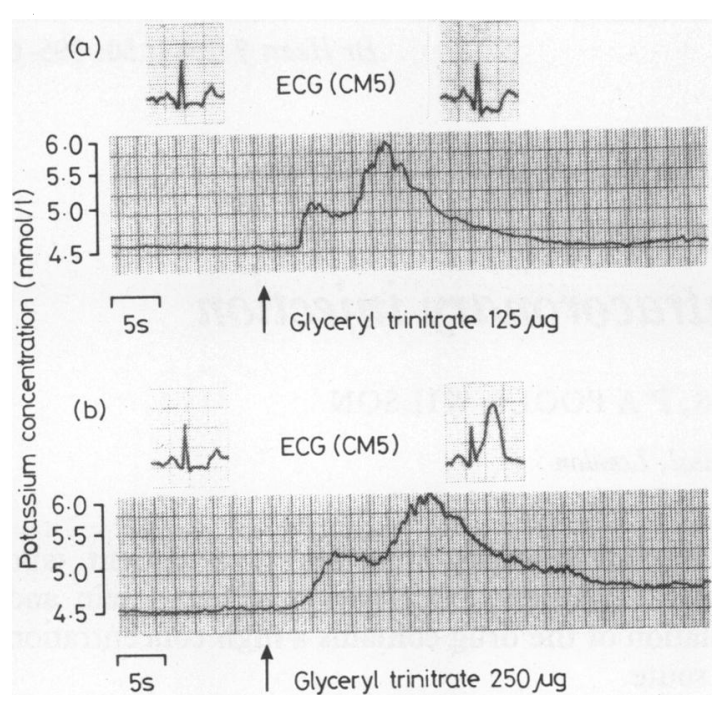

Fig. Continuous recordings of coronary sinus potassium concentration showing the effects of intracoronary injections of glyceryl trinitrate at doses of $125 \mu \mathrm{g}(a)$ and $250 \mu \mathrm{g}(\mathrm{b})$. Sections of the surface electrocardiogram (lead CM5) before and after each injection are also shown. ECG, electrocardiogram.

tose, and monobasic potassium phosphate. The potassium concentration was not specified on the data sheet but inquiries revealed that it is $100 \mathrm{mmol} / /$. When diluted to give a glyceryl trinitrate concentration of $200 \mu \mathrm{g} / \mathrm{ml}$ (as used in this case) the resulting solution has a potassium concentration of $40 \mathrm{mmol} / 1$.

Intracoronary injection of such a solution can cause changes on the electrocardiogram. Animal experiments have shown that regional hyperkalaemia results in $\mathrm{T}$ wave inversion with low doses of intracoronary potassium whereas higher doses produce ST elevation with $T$ wave peaking. ${ }^{3}$ Our observations closely resemble those findings. A local increase in potassium concentration is a factor in initiating ventricular arrhythmias, ${ }^{3}$ particularly in the context of myocardial ischaemia. ${ }^{4}$ Although our patient remained in sinus rhythm, arrhythmias represent a potential hazard of giving intracoronary injections containing high concentrations of potassium. A further risk arises from the vasoactive properties of potassium. At high concentrations $(>15 \mathrm{mmol} / \mathrm{l})$ potassium causes smooth muscle contraction in isolated arterial preparations. ${ }^{5}$ The exacerbation of chest pain experienced by our patient after each intracoronary injection may therefore have been caused by aggravation of myocardial ischaemia due to coronary vasospasm. Such problems can be avoided by using a preparation of glyceryl trinitrate that does not contain potassium.

\section{References}

1 Bentivoglio LG, Grüntzig A. Relief by intracoronary glyceryl trinitrate of coronary artery spasm resistant to sublingual route of administration. Br Heart $\mathcal{f} 1981$; 46: 581-3.

2 Pepine CJ, Feldman RL, Conti CR. Action of intracoronary nitroglycerin in refractory coronary artery spasm. Circulation 1982; 65: 411-4.

3 Soloff LS, deLos Santos GA, Oppenheimer MJ. Electrocardiographic changes produced by potassium and other ions injected into the coronary arteries of intact dogs. Circ Res 1960; 8: 479-84.

4 Harris AS. Potassium and experimental coronary occlusion. Am Heart f 1966; 71: 797-802.

5 Norton JM, Detar R. Potassium and isolated coronary vascular smooth muscle. Am f Physiol 1972; 222: 474-9.

Requests for reprints to Professor P A Poole-Wilson, Cardiothoracic Institute, 2 Beaumont Street, London W1N 2DX. 